\title{
Psychiatric Morbidities among Female Sex Workers in Bangladesh: an Observational Study
}

\author{
Dr. Fahmida Ferdous ${ }^{1 *}$, Dr. Md Faruq Alam² ${ }^{2}$ Dr. Helal Uddin Ahmed ${ }^{3}$, Dr. Md. Samsul Ahsan ${ }^{4}$, Dr. \\ Dionéia Motta Monte-Serrat ${ }^{5}$ \\ ${ }^{1}$ Assistant Professor, Department of Psychiatry, Z H Sikder Women's Medical College, Dhaka, Bangladesh \\ ${ }^{2}$ Professor Department of Psychiatry, National Institute of Mental Health (NIMH), Sher-E-Bangla Nagar, Dhaka, \\ Bangladesh \\ ${ }^{3}$ Associate Professor, Department of Psychiatry, National Institute of Mental Health (NIMH), Sher-E-Bangla Nagar, \\ Dhaka, Bangladesh \\ ${ }^{4}$ Associate Professor, Department of Psychiatry, Bagabandhu Sheikh Mujib Medical University, Dhaka, Bangladesh \\ ${ }^{5}$ Assistant Ph.D. Professor at Post-doc in Computation and Mathematics, FFCLRP-USP, University of Ribeirao Preto, \\ UNAERP, Collaborating Researcher IEL-UNICAMP, Brazil
}

\section{*Corresponding Author}

Dr. Fahmida Ferdous

\author{
Article History \\ Received: 19.09 .2020 \\ Accepted: 28.09 .2020 \\ Published: 02.10.2020
}

\begin{abstract}
Female sex workers are degraded by society all over the world. Most of them suffered from depression and different sorts of mental disorders are developed among them. To find out the psychiatric disorders among female sex worker seeking medical treatment in a STI/RTI treatment centre run by Non Governmental Organization (NGO), Dhaka. This cross-sectional study was conducted at outdoor treatment centre of an NGO in Dhaka city from January 2019 to December 2019 over a period of one year. Fifty female sex workers were selected for this study. The mean age of the respondents was $33.2 \pm 7.9$ years within the range of $21-47$ years. Almost two-thirds of the respondents just completed their primary education and $22.0 \%$ of the respondents were illiterate. Maximum respondents were either single or live away from family. Only $32.0 \%$ of the respondents lived with their respective husbands. More than half of the respondents had no good relationship with their respective husbands. The average monthly income was 235 US Dollar (USD). Income varied from 47 USD to 588 USD. About $36 \%$ of respondents had family members more than 04 persons. Family members varied from 01 to 07 . As a sex partner, most of the respondents preferred males and the most preferable route was mouth. $38.0 \%$ of the respondents used barrier and $18.0 \%$ of the respondents had a selective client. According to DSM-5, Major Depressive Disorders was observed in 62\% respondents, Substance/medication-induced psychotic disorder $18 \%$, anti-social personality disorder was observed in $08 \%$ respondents and Histrionic personality disorder was observed in $12.0 \%$ respondents. The prevalence of Psychiatric morbidities is an under attended problem in Bangladesh. To the author's best knowledge this is the first psychiatrist approach to female sex workers in Bangladesh .Further large scale extensive studies would be necessary for better visualization of the extent of the issue.
\end{abstract}

Keywords: Psychiatric, morbidity, female sex worker.

\section{INTRODUCTION}

A female sex worker is defined as a woman who is in a sexual relationship with a man other than her partner when there is a financial incentive involved. Female sex workers suffer from a dilemma from a common belief that they are living with adultery, ruining relationships, spreading venereal disease, and giving birth to illegitimate children. Also, their work is strongly forbidden by religious laws with certain extreme punishments. For this reason, female sex workers conceal their real identity while interacting with their clients and living in society [1-3]. Combination of many factors like cultural and legal barriers, female sex workers are a deprived part of communities [4] and it is very difficult to gather information $^{5}$ and perform a psychiatric study on female sex workers in Bangladesh although various non-governmental organization (NGO), such as BWHC (Bangladesh Woman's Health Coalition), DNS (Durjoy Nari Shangha) and Light

Copyright @ 2020: This is an open-access article distributed under the terms of the Creative Commons Attribution license which permits unrestricted use, distribution, and reproduction in any medium for non commercial use (NonCommercial, or CC-BY-NC) provided the original author and source are credited. 
House are the STI/RTI treatment centres in Bangladesh play a significant role in helping female sex workers with their sexual health. Sex workers are vulnerable population who are prone to many health conditions including medical diseases such as sexually transmitted diseases (STDs) as well as psychiatric disorders [1-3]. The psychosocial vulnerabilities and mental stressor including, childhood sexual abuse, exposure to childhood physical abuse, poverty, illiteracy, low socioeconomic status various interpersonal violence that is unfavourable to family conditions [6-8] such as conflicts with own family, make these vulnerable patients more susceptible to psychiatric disorders. Female sex work face disproportionate social and health inequities compared to the general population, there remains a treatment gap in evidence regarding the broader general health issues faced by this group of female sex workers, including psychiatric morbidity [5]. The mental health of female sex works remains sparse and is limited to only a few studies settings in Asia, Europe, North America, and Australia. Evidence from various studies indicates that female sex workers may experience a high burden of psychiatric morbidity, especially mood disorder, suicidal ideation due to Major Depressive Disorders, and post-traumatic stress disorder (PTSD) [9-17] and substance use [6]. The objective of this study was to diagnosis psychiatric morbidity among female sex workers in Bangladesh to develop evidence-based mental health interventions and to reduce their impact on their well-being.

\section{METHOD}

This cross-sectional study was conducted in an NGO outpatient facility where clients came for the treatment of Sexually Transmitted Infection/Reproductive Transmitted Infection (STI/RTI) in Dhaka city. Study period was one year from January 2019 to December 2019. These STI/RTI treatment centres, funded by different Non Governmental organizations, are situated different part of the city. One female sex worker is assigned as informer to inform other sex workers in that particular area for STI/RTI treatment. The treatment facility is designed to treat STI/RTI of the female sex workers by a female doctor. Whenever FSWs visited the centre for STI/RTI treatment first author approached them with the study. Objective of the study, anonymity of the participants and detail of confidentiality were explained to each FSW. They were also explained that even after the consent they can withdraw themselves any time from the study. After taking written and verbal consent from fifty FSWs, Socio-demographic data were obtained and psychiatric diagnoses were performed using Diagnostic and Statistical Manual (DSM-V). Collected data were sorted, cleaned and analysed.

\section{RESULTS}

The duration of study was one year. Participation rate 70.4\% (Twenty one FSWs were refused to enroll in this study). Mean age of the respondents was $33.2 \pm 7.9$ years within the range of $21-47$ years. Half of the respondents were in age group 21-30 years. Most of the respondents were Muslim (94.0\%). Most of the respondents did not completed secondary school. Almost two third of the respondents just completed their primary education and $22.0 \%$ of the respondents were illiterate. Maximum respondents did not live either with husbands or parents, only $20.0 \%$ of the respondents lived with their respective husbands. Very few of the respondents had good relationship with their respective husbands.

Table-1: Demographic profile of the respondents $(\mathrm{N}=50)$

\begin{tabular}{|c|c|c|}
\hline & Frequency $(\mathbf{n})$ & Percentage (\%) \\
\hline \multicolumn{3}{|l|}{ Age (years) } \\
\hline $21-30$ & 25 & 50.0 \\
\hline $31-40$ & 13 & 26.0 \\
\hline $41-50$ & 12 & 24.0 \\
\hline Mean \pm SD (min-max) & \multicolumn{2}{|c|}{$33.2 \pm 7.9(21-47)$} \\
\hline \multicolumn{3}{|l|}{ Religion } \\
\hline Muslim & 47 & 94.0 \\
\hline Hindu & 3 & 6.0 \\
\hline \multicolumn{3}{|l|}{ Education } \\
\hline Illiterate & 11 & 22.0 \\
\hline Primary & 32 & 64.0 \\
\hline Class VIII & 6 & 12.0 \\
\hline SSC & 1 & 2.0 \\
\hline \multicolumn{3}{|l|}{ Occupation } \\
\hline Business & 38 & 76.0 \\
\hline Service & 12 & 24.0 \\
\hline \multicolumn{3}{|l|}{ Living with } \\
\hline Husband & 10 & 20.0 \\
\hline Parents & 16 & 32.0 \\
\hline Others & 24 & 48.0 \\
\hline \multicolumn{3}{|l|}{ Relation with husband } \\
\hline Good & 06 & 12.0 \\
\hline Bad & 44 & 88.0 \\
\hline
\end{tabular}


Table-2: Respondents' monthly income $(\mathrm{N}=50)$

\begin{tabular}{|l|c|c|}
\hline Monthly income (Taka) & Frequency $(\mathbf{n})$ & Percentage $(\boldsymbol{\%})$ \\
\hline$\leq 10,000$ & 11 & 22.0 \\
\hline$>10,000-20,000$ & 25 & 50.0 \\
\hline$>20,000$ & 14 & 28.0 \\
\hline Mean \pm SD (min-max)US\$ & \multicolumn{2}{|c|}{$235 \pm 143(47-588)$} \\
\hline
\end{tabular}

US\$ $1.0=$ Tk. 85.0 (Aprox)

Average monthly income of the female sex workers was US\$235. Income varied from US\$ 47 to US\$ 588. Half of the respondent's monthly income was between US\$ 117 - US\$235. Here most of the respondent's income was more than per capita of Bangladesh (78.0\%). Per capita income per month is US\$ 107.3 [18].

Table-3: Respondents' family member $(\mathbf{N}=50)$

\begin{tabular}{|l|c|c|}
\hline Family member & Frequency $(\mathbf{n})$ & Percentage (\%) \\
\hline $1-2$ & 13 & 26.0 \\
\hline $3-4$ & 19 & 38.0 \\
\hline$>4$ & 18 & 36.0 \\
\hline Mean \pm SD & $3.9 \pm 1.7$ & \\
\hline Min $-\max$ & $1-7$ & \\
\hline
\end{tabular}

$36.0 \%$ respondents had family member more than 4 persons. Family member varied from 1 to 7.

Table-4: Liking of the respondents $(\mathrm{N}=50)$

\begin{tabular}{|l|c|c|}
\hline & Frequency (n) & Percentage (\%) \\
\hline Like as a sex partner & & \\
\hline Male & 49 & 98.0 \\
\hline Female & 1 & 2.0 \\
\hline Preferred route & & \\
\hline Mouth & 30 & 60.0 \\
\hline Vagina & 09 & 18.0 \\
\hline Both(Mouth \& Vagina) & 10 & 20.0 \\
\hline Anus & 01 & 2.0 \\
\hline Barrier method(Condom) used by the respondents & 19 & 38.0 \\
\hline Selective partner & 9 & 18.0 \\
\hline
\end{tabular}

As a sex partner most of the respondents' preferred male and most preferable route was mouth.38.0\% of the respondents used barrier and $18.0 \%$ of the respondents had selective client.

Table-5: DSM 5 diagnosis $(\mathrm{N}=50)$

\begin{tabular}{|l|c|c|}
\hline & Frequency (n) & Percentage (\%) \\
\hline Major depressivedisorder & 31 & 62.0 \\
\hline Substance/medication-induced psychotic disorder & 09 & 18.0 \\
\hline Histrionic personality disorder & 06 & 12.0 \\
\hline Antisocial personality disorder & 04 & 8.0 \\
\hline
\end{tabular}

*Multiple responses

According to DSM 5, Major depressive disorder was observed in 62.0\% respondents, Substance/medicationinduced psychotic disorder was $18.0 \%$, Anti-social personality disorder was observed in $8.0 \%$ respondents and Histrionic personality disorder was observed in $12.0 \%$ respondents.

\section{DisCUSSION}

Bangladesh is a country with tolerant and Muslim majority country. Yet prostitution is legal in here. The societal view of prostitution is not positive for definite reason and it's a disrespected profession. There is a scarcity of data regarding psychiatric disorders among female sex workers (FSWs) in Bangladesh. Due to cultural and religious barriers, information gathering, and release for the topic of sex workers have been often extremely difficult. In present study psychiatric diagnosis was done by face to face interview assigned using DSM-V among the respondents. In this study, Major Depressive Disorder among female sex workers was $62 \%$ which was comparable to the studies of Sagtani $e t$ al., conducted in Nepal, Suresh et al., \& Pandiyan et al., in India and Alegria et al., in Puerto Rico [19-22]. The guilt of 
being into this profession was also causing them depression. Among the FSWs, in this study, $18.0 \%$ were substance/medication-induced psychotic disorder. Substance use is a common practice among sex workers. To earn more need to entertain more clients, this is not possible without substance use. Histrionic personality disorder was found in $12.0 \%$ cases and antisocial personality disorder in $8.0 \%$ cases. There is a high rate of antisocial personality disorder (APD) and other psychiatric morbidities in prostitute women [23].

In this study, the mean age of the FSWs was $33.2 \pm 7.9$ years varied from 21 to 47 years. Half of the respondents were in the age group 21-30 years. In a study conducted in Meghalaya of India mean age of the respondents was 29.53 years and the majority of them were Christian [24]. In our study, most of the respondents were Muslim (94.0\%) as because Muslim majority country. Most of the respondents did not complete secondary school. Almost two-thirds of the respondents just completed their primary education and $22.0 \%$ of the respondents were illiterate. The majority of the FSW completed primary education only in Miraj Town of India [8]. In the study of Iaisuklang and Ali, majority of the FSW studied up to middle school in Meghalaya of India [6]. Poverty is one of the main causes which push woman towards prostitution. Economically depressed women with low education levels become victims of prostitution. Maximum respondents did not live with either husbands or parents, only $20.0 \%$ of the respondents lived with their respective husbands. More than half of the respondents had no good relationship with their respective husbands.

The average monthly income was US\$235. Income varied from US\$ 47 to US\$ 588. Half of the FSWs' monthly income was between US\$ 117.6 to US\$ 235. Here most of the FSWs' income was more than per capita of Bangladesh (78.0\%). In Bangladesh, per capita income per month is US\$ 107.3 [18]. FSWs' of this study were not from any brothel, they live within the general population and maintained better lifestyle to attract sophisticated clients. That is why they earn a handsome amount.

As a sex partner, most of the FSWs preferred males and the most preferable route was mouth. $38.0 \%$ of the FSWs used barrier and $18.0 \%$ of the FSWs had selective clients. $62.0 \%$ of the FSWs were in danger of sexually transmitted diseases. They have a lack of health awareness, so, public health policymakers must have knowledge about their mental health status. Lack of safe sex practice may be a major threat of STI transmission in the society. More than 1 million sexually transmitted infections (STIs) are acquired every day worldwide. Each year, there are an estimated 376 million new infections with 1 of 4 STIs: chlamydia, gonorrhoea, syphilis and trichomoniasis [24, 25].

The ambivalence of FSWs identity gives rise to different forms of alienation. From the perspective of Lacanian psychoanalysis, importance is given to alterity in the constitution of identity [26]. The subject is the object of another person's gaze and is structured from that other in a mental operation [27]. For Lacan, alterity is the point from which the subject sees himself; it is from the otherness that he describes himself [26-28]. As the female sex worker does not experience a relationship of continuity, but a transient, illusory relational situation, the construction of her own identity suffers negative interference. In addition to health treatment, special attention should be paid to psychological treatment of female sex workers, so that they can reconstruct their own image, dismantling the distorted image and setting up their identity in a new structure.

\section{Conclusion}

Mental health is a significant part of overall health preventive intervention. The prevalence of psychiatric morbidity among female sex workers is notable in Bangladesh, for a healthier lifestyle of female sex workers we need to reduce the psychiatric morbidities to help their well-being. Finally, there is an immediate need to improve their wellbeing, develop evidence-based assessment and diagnosis of psychiatric morbidities, through governmental and nongovernmental agencies in Bangladesh, and also through mental health professionals and prevention workers.

\section{REFERENCES}

1. Shen, H., Zou, H., Huang, S., Liu, F., Zhao, P., Chen, L., ... \& Yang, B. (2016). Depression and HIV risk behaviors among female sex workers in Guangdong, China: a multicenter cross-sectional study. BioMed research international, 2016.

2. Patel, S. K., Saggurti, N., Pachauri, S., \& Prabhakar, P. (2015). Correlates of mental depression among female sex workers in Southern India. Asia Pacific Journal of Public Health, 27(8), 809-819.

3. Sagtani, R. A., Bhattarai, S., Adhikari, B. R., Baral, D., Yadav, D. K., \& Pokharel, P. K. (2013). Violence, HIV risk behaviour and depression among female sex workers of eastern Nepal. BMJ open, 3(6):e002763.

4. Ranjbar, F., Sadeghi-bazargani, H., Pishgahi, A., Nobari, O., Farahbakhsh, M., Farhang, S., ... \& Dareshiri, S. (2019). Mental health status among female sex workers in Tabriz, Iran. Archives of women's mental health, 22(3), 391-397.

5. Puri, N., Shannon, K., Nguyen, P., \& Goldenberg, S. M. (2017). Burden and correlates of mental health diagnoses among sex workers in an urban setting. BMC women's health, 17(1), 133. 
6. Iaisuklang, M. G., \& Ali, A. (2017). Psychiatric morbidity among female commercial sex workers. Indian journal of psychiatry, 59(4), 465.

7. Sagtani, R. A., Bhattarai, S., Adhikari, B. R., Baral, D. D., Yadav, D. K., \& Pokharel, P. K. (2014). Understanding socio economic contexts of female sex workers in eastern Nepal. Nepal Med Coll J, 16(2-4), 119-124.

8. Gadekar, U. (2015). Socio-economic status and health challenges of female sex workers of Miraj Town, India. Children, 7, 23-3.

9. Benoit, C., Atchison, C., Casey, L., Jansson, M., McCarty, B., Phillips, R., ... \& Shaver, F. M. (2014). A" working paper" prepared as background to Building on the Evidence: An International Symposium on the Sex Industry in Canada. Gender, Violence and Health.

10. Gu, J., Lau, J. T., Li, M., Li, H., Gao, Q., Feng, X., ... \& Hao, Y. (2014). Socio-ecological factors associated with depression, suicidal ideation and suicidal attempt among female injection drug users who are sex workers in China. Drug and alcohol dependence, 144, 102-110.

11. Sanders, T. (2004). A continuum of risk? The management of health, physical and emotional risks by female sex workers. Sociology of health \& illness, 26(5), 557-574.

12. Rössler, W., Koch, U., Lauber, C., Hass, A. K., Altwegg, M., Ajdacic- Gross, V., \& Landolt, K. (2010). The mental health of female sex workers. Acta psychiatrica scandinavica, 122(2), 143-152.

13. Surratt, H. L., Kurtz, S. P., Chen, M., \& Mooss, A. (2012). HIV risk among female sex workers in Miami: the impact of violent victimization and untreated mental illness. AIDS care, 24(5), 553-561.

14. Roxburgh, A., Degenhardt, L., \& Copeland, J. (2006). Posttraumatic stress disorder among female street-based sex workers in the greater Sydney area, Australia. BMC psychiatry, 6(1), 24.

15. Surratt, H. L., Kurtz, S. P., Weaver, J. C., \& Inciardi, J. A. (2005). The connections of mental health problems, violent life experiences, and the social milieu of the "stroll" with the HIV risk behaviors of female street sex workers. Journal of Psychology \& Human Sexuality, 17(1-2), 23-44.

16. Ulibarri, M. D., Hiller, S. P., Lozada, R., Rangel, M. G., Stockman, J. K., Silverman, J. G., \& Ojeda, V. D. (2013). Prevalence and characteristics of abuse experiences and depression symptoms among injection drug-using female sex workers in Mexico. Journal of environmental and public health, 2013.

17. Su, S., Li, X., Zhang, L., Lin, D., Zhang, C., \& Zhou, Y. (2014). Age group differences in HIV risk and mental health problems among female sex workers in Southwest China. AIDS care. 26(8):1019-26.

18. Trading Economics. Bangladesh GDP per capita income. 2020. Available at: https://tradingeconomics.com/bangladesh/gdp-per-capita Viewed on 09-08-2020

19. Sagtani, R. A., Bhattarai, S., Adhikari B. R., Baral, D., Yadav, D. K., \& Pokharel, P. K. (2013). Violence, HIV risk behaviour and depression among female sex workers of eastern Nepal. BMJ open. 3(6).

20. Suresh, G., Furr, L. A., \& Srikrishnan, A. K. (2009). An assessment of the mental health of street-based sex workers in Chennai, India. Journal of Contemporary Criminal Justice. 25(2):186-201.

21. Pandiyan, K., Chandrasekhar, H., \& Madhusudhan, S. (2012). Psychological morbidity among female commercial sex workers with alcohol and drug abuse. Indian journal of psychiatry. 54(4):349.

22. Alegria, M., Vera, M., Freeman, Jr D. H., Robles, R., Santos, M. D., \& Rivera, C. L. (1994). HIV infection, risk behaviors, and depressive symptoms among Puerto Rican sex workers. American Journal of Public Health. 84(12):2000-2.

23. Brody, S., \& Potterat, J. J. (2010). Assessing mental health and personality disorder in prostitute women. Acta Psychiatrica Scandinavica, 122(2):167.

24. Rowley, J., Vander Hoorn, S., Korenromp, E., Low, N., Unemo, M., Abu-Raddad, L. J., \& Chico, R. (2019). Global and regional estimates of the prevalence and incidence of four curable sexually transmitted infections in 2016 . WHO Bulletin. June.

25. Report on global sexually transmitted infection surveillance, 2018. Geneva: World Health Organization; 2018. Licence: CC BY-NC-SA 3.0 IGO] https://www.who.int/reproductivehealth/publications/stis-surveillance-2018/en/

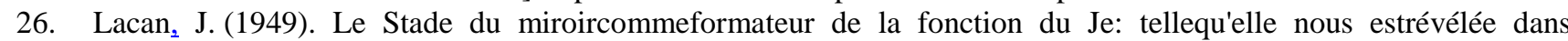
l'expériencepsychanalytique, Presses universitaires de France.

27. Roudinesco, E. (1997). Dictionnaire de la Psychanalyse. Paris: Fayard.

28. Lacan, J. (1964). Le Séminaire de Jacques Lacan Livre XI: Les quatre concepts fondamentaux de la psychanalyse. 